\title{
Retraction Note: News propaganda of rural rainfall slope stability and environmental protection based on image reconstruction
}

\author{
Wei Wang ${ }^{1}$
}

Published online: 6 December 2021

C) Saudi Society for Geosciences 2021

Retraction Note: Arabian Journal of Geosciences (2021) 14: 1577 https://doi.org/10.1007/s12517-021-07976-6

The Editor-in-Chief and the Publisher have retracted this article because the content of this article is nonsensical. The peer review process was not carried out in accordance with the Publisher's peer review policy. The author has not responded to correspondence regarding this retraction.

The original article can be found online at https://doi.org/10.1007/ s12517-021-07976-6.

Wei Wang

wei2021cg@163.com

1 Department of Humanities and Social Science,

Hebei University of Environmental Engineering,

Qinhuangdao 066000, Hebei, China 